\title{
Preclinical Safety Evaluation of Acute and Subacute Intranasal Administration of Polyphenols-based Cinnamon Bark Extract in Laboratory Rats
}

\author{
Prasad Thakurdesai' ${ }^{1}$ Pallavi Deshpande ${ }^{1, *}$
}

Prasad Thakurdesai', Pallavi Deshpande ${ }^{1, *}$

${ }^{1}$ Department of Scientific Affairs, Indus Biotech Private Limited, Kondhwa, Pune, Maharashtra, INDIA.

\section{Correspondence}

\section{Pallavi Deshpande}

Department of Scientific Affairs, Indus Biotech Private Limited, 1 Rahul Residency, Off Salunke Vihar Road, Kondhwa, Pune -

411 048, Maharashtra, INDIA

Phone no: +91 206478 5063/64;

Fax: +912026850039

E-mail: pallavi@indusbiotech.com

History

- Submission Date: 23-09-2021;

- Review completed: 26-10-2021;

- Accepted Date: 02-11-2021.

DOI : 10.5530/pj.2021.13.209

Article Available online http://www.phcogj.com/v13/i6

Copyright

(C) 2021 Phcogj.Com. This is an openaccess article distributed under the terms of the Creative Commons Attribution 4.0 International license.

\begin{abstract}
Background: Polyphenols-based standardized cinnamon (Cinnamomum zeylanicum) bark extract (IND02) demonstrated efficacy against allergic rhinitis in animal models and human clinical study. Objectives: To assess the acute and subacute intranasal toxicity of the IND02 nasal solution (IND02-NS). Methods: Acute and 28-days subacute toxicity using the intranasal route of administration of IND02-NS was evaluated using Wistar rats as per Organisation for Economic Co-operation and Development guidelines. For acute intranasal toxicity study, a single dose of $100 \mu \mathrm{g} / \mathrm{rat} /$ day was administered in five male and female rats and observed for the incidence of mortality and signs of toxicity for 14 days. For a 28-days subacute intranasal toxicity study, doses of 20,50, and $100 \mu \mathrm{g} / \mathrm{rat} / \mathrm{day}$ were administered to a group of five male and female rats. Results: The IND02-NS did not show mortality or treatment-related adverse signs during acute (limit dose of $100 \mu \mathrm{g} / \mathrm{rat} /$ day) and subacute intranasal (28-days repeated dose of 20,50 , and $100 \mu \mathrm{g} / \mathrm{rat} /$ day with 14 days of reversal period) administration. The IND02-NS showed a maximum tolerated dose greater than $100 \mu \mathrm{g} / \mathrm{rat}$ during the acute intranasal toxicity study. The no-observed adverse effect level of IND02-NS was $100 \mu \mathrm{g} / \mathrm{rat} / \mathrm{day}$ in rats during the subacute intranasal toxicity study. Conclusion: IND02-NS was found safe at $100 \mu \mathrm{g} / \mathrm{rat} / \mathrm{day}$ during acute and subacute (28 days repeated dose) for nasal administration in rats. Key words: Intranasal toxicity, Standardized cinnamon bark, Polyphenols, Maximum tolerated dose, Noobserved-adverse-effect level.
\end{abstract}

\section{INTRODUCTION}

The cinnamon (Cinnamomum zeylanicum) bark is one of the oldest herbal medicines cultivated in many tropical countries, including China, India, Brazil, Madagascar, Mexico, and the Caribbean. Worldwide is used as a spice due to its health benefits, flavors, and food preservation properties. $^{1-3}$ In modern scientific literature, cinnamon bark has been reported to have various medicinal properties ${ }^{4-13}$. The cinnamon bark is used as an ingredient of many medicinal natural products for the treatment of diverse immuneinflammatory disorders due to antioxidant, ${ }^{13,14}$ and anti-inflammatory ${ }^{15}$ properties.

The procyanidins polyphenols are the oligomeric end-products of the flavonoid biosynthetic pathway with (+)- catechin and (-)-epicatechin as a building block ${ }^{16}$. Cinnamon bark contains many polyphenols (PP), including type A procyanidin polyphenols, which are reported as anti-inflammatory and antibacterial compounds in vitro ${ }^{17-19}$. The recent scientific research on the procyanidins polyphenolic oligomers containing flavan-3-ols and their oligomeric forms (proanthocyanidins) from cinnamon bark demonstrated a high potential for therapeutic use $\mathrm{e}^{20-22}$.

The polyphenols-based standardized cinnamon bark extract (IND02) had reported beneficial effects on humoral (antibody production), cellular and innate responses of the immune system, as well as numbers of resident peritoneal macrophages during in vivo and ex vivo studies ${ }^{23}$. Furthermore, series of in vitro experiments demonstrated potent entry inhibition properties of IND02 against the hepatitis $\mathrm{C}$ virus ${ }^{24-26}$ and human immunodeficiency virus-1 ${ }^{26,27}$. The IND02 is reported to block the selectin binding and leukocytes adhesion with sialic acids to inhibit allergic inflammation ${ }^{28}$, inhibit the markers of allergic rhinitis (AR) such as histamine, Interleukin 4 (IL-4), and $\beta$ - hexosaminidase in an Immunoglobulin $\mathrm{E}$ inhibition ${ }^{29}$, and mast cell stabilizing mechanisms ${ }^{29}$. Topical intranasal use of IND02-NS showed good efficacy against AR during animal studies ${ }^{30}$ and patients ${ }^{31,32}$. However, the long-term safety of intranasal administration of IND02-NS is not yet reported. Therefore, the present study aimed at safety and toxicological evaluation IND02-NS in rats following the acute and subacute intranasal administration as per international standards established by Organization for Economic Cooperation and Development (OECD) guidelines.

\section{MATERIALS AND METHODS}

\section{Animals}

The Wistar rats (120-200 g) of either sex and 7-week old were purchased from Taconic Biosciences, Inc. USA and used. The rats were acclimatized for seven days before dosing. The markings were done on cages and individual rats for identification. Rats were fed on pelleted feed (Altromin Spezialfutter $\mathrm{GmbH}$ and Co. KG, Germany, supplied by ATNT Laboratories, Mumbai, India) and provided with pure potable water in sterilized bottles with stainless steel sipper tubes. The rats were maintained at ambient temperature $\left(19-25^{\circ} \mathrm{C}\right)$ and relative humidity $(30-70 \%)$ with $12 \mathrm{~h}: 12 \mathrm{~h}$ of the dark: light cycle. The female rats were nulliparous and non-pregnant. The study

Cite this article: Thakurdesai $P$, Deshpande P. Preclinical Safety Evaluation of Acute and Subacute Intranasal Administration of Polyphenols-based Cinnamon Bark Extract in Laboratory Rats. Pharmacogn J. 2021;13(6)Suppl: 1621-1631. 
protocol was approved by the Institutional Animal Ethics Committee of INTOX Pvt Ltd, Pune, India (Approval number: 17051 and 17052).

\section{The test compound, IND02 solution (IND02-NS)}

The test compound, IND02-NS, the solution of IND02 powder in saline, was provided by Indus Biotech Private Limited, Pune, with $64.82 \mathrm{mcg}$ per 100 microliters of polyphenols content as analyzed by the FolinCiocalteu reagent method ${ }^{33}$. The IND02 powder is a standardized extract of cinnamon bark with $77.5 \%$ polyphenols content as analyzed by the Folin-Ciocalteu reagent method ${ }^{33}$.

The maximum volume that can be administered intranasally to the rats is reported to be $50 \mu \mathrm{l} /$ nostril ${ }^{34}$. To administer the intranasal dose within the specific volume limits of $50 \mu \mathrm{l}$ per nostril, the stock solution of IND02 (IND02-NS) of $1 \mathrm{mg} / \mathrm{ml}$ concentration was prepared. IND02-NS was diluted daily to prepare different doses in the same volume of $25 \mu \mathrm{l}$ solution per nostril per time. Hence, the total daily volume of $100 \mu \mathrm{l}$ solution per rat per day $(50 \mu \mathrm{l}$ per nostril per day) was administered in two divided doses, i.e., first dose $(25 \mu$ l solution per nostril) in the morning (am) and second dose $(25 \mu \mathrm{l}$ solution per nostril) in the afternoon (pm).

Based on the surface area ratio of humans and rats, the maximum daily dose of $100 \mu \mathrm{g} / \mathrm{rat} /$ day was found almost ten times lower than the reported maximum safe intranasal human equivalent dose $=1143 \mu \mathrm{g}$ per day ${ }^{35}$. Thus, the doses of $100 \mu \mathrm{g}$ (highest dose), $50 \mu \mathrm{g}$ (middle dose), and $20 \mu \mathrm{g}$ (lowest dose) per rat per day were finalized for the toxicology evaluation part of the present study.

\section{Acute intranasal toxicity (AINT) study}

The acute toxicity study of IND02-NS was performed with the intranasal route of administration. The dose of $100 \mu \mathrm{g} / \mathrm{rat} / \mathrm{day}$ was intranasally administrated in groups of five rats per sex. The rats were observed for 14 days for any signs of morbidity or mortality.

\section{Subacute (28-day repeated dose) intranasal toxicity study}

The study was carried out as per OECD guidelines (Test No. 407, "Repeated Dose 28-Day Oral Toxicity Study in Rodents" ${ }^{36}$ with the nasal route of administration. In addition, the buried food test was carried out on all rats to assess the sense of smell ${ }^{37}$. Sixty rats, i.e., 30 male and 30 healthy female rats, were randomly divided into six groups of 5 rats each. The IND02-NS solution was intranasally administered as $25 \mu \mathrm{l} /$ nostril, twice a day, i.e., $100 \mu \mathrm{l} /$ rat to groups of rats with the help of micropipette as follows:

- G1 - VC - Vehicle (100 $\mu \mathrm{l} /$ rat/day) for 28 days

- G2 - IND02-NS-20 group - IND02-NS (20 $\mu \mathrm{g} / \mathrm{rat} /$ day $)$ for 28 days

- G3 - IND02-NS-50 group - IND02-NS (50 $\mu \mathrm{g} / \mathrm{rat} /$ day) for 28 days

- G4 - IND02-NS-100 group - IND02-NS (100 $\mu \mathrm{g} / \mathrm{rat} / \mathrm{day})$ for 28 days

- G1R - VC-R group - Vehicle $100 \mu \mathrm{l} /$ rat/day for 43 days

- G4R - IND02-NS-100R group - IND02-NS (100 $\mu \mathrm{g} / \mathrm{rat} /$ day) for 28 days and vehicle $100 \mu \mathrm{l} / \mathrm{rat} /$ day for the next 14 days (Day 29 to Day 43).

Clinical signs, mortality, body weight, and feed consumption

All rats were observed daily for mortality and clinical signs. The detailed clinical examination was carried out before initiation of treatment and weekly during the treatment and reversal period. The weight of each rat and food consumption were recorded at weekly intervals throughout the study period. In the $4^{\text {th }}$ week of treatment, all animals were examined for assessment of sensory reactivity, grip strength and motor activity as a part of functional observation test.

\section{Buried Food Test}

The buried food test relies on the animal's natural tendency to use olfactory cues for foraging and is used to confirm the ability to smell odors ${ }^{37}$. The effect of IND02-NS on the olfactory system was carried out before initiation of treatment (day 0 ) and weekly thereafter, during the study as per reported procedure ${ }^{37}$. The buried food test measures a time to find buried food, i.e. when an overnight fasted animal can find a small piece of food palette hidden under a layer of bedding ${ }^{37}$. On the test day, rats fasted and water ad libitum for $18 \mathrm{~h}$ to $20 \mathrm{~h}$ before the test. Then each rat was placed in a clean cage containing $3 \mathrm{~cm}$ deep clean bedding and was allowed to acclimatize to the cage for $5 \mathrm{~min}$. After 5 min, the rat was transferred to another empty, clean cage. A measured quantity of food ( 2 food pellets) was buried together approximately 1 $\mathrm{cm}$ beneath the surface at one corner of the cage. The surface of bedding was smoothened. The rat was re-introduced to the cage, the timer was started, and the time to find the buried food by rat was recorded. If the animal failed to find the buried food after $15 \mathrm{~min}$, the test was stopped, and a cut-off period of 15 min was recorded ${ }^{37}$.

\section{Laboratory evaluations}

Urine and blood samples were collected for laboratory evaluations (hematology, biochemistry, and urinalysis) from all rats in the 28-day study and the reversal groups during the last week of the treatment period, before the scheduled necropsy. The hematological evaluations include Hemoglobin (Hb), packed cell volume (PCV), red blood corpuscles (RBC), mean corpuscular hemoglobin $(\mathrm{MCH})$, mean corpuscular volume (MCV), mean corpuscular hemoglobin concentration (MCHC), total leukocyte count (TLC), neutrophils (N), lymphocytes (L), monocytes (M), eosinophils (E), basophils (B), platelets, reticulocytes, activated partial thromboplastin time (APTT) and prothrombin time (PT). The biochemistry parameters include total protein, albumin, globulin, alanine aminotransferase (ALT), aspartate aminotransferase (AST), alkaline phosphatase (ALP), glucose, blood urea nitrogen (BUN), urea, creatinine, cholesterol, gamma-glutamyl transferase (GGT), total bile acid, triglyceride, total bilirubin, sodium $(\mathrm{Na})$, potassium $(\mathrm{K})$, calcium $(\mathrm{Ca})$, phosphorus $(\mathrm{P})$ and albumin to globulin ratio (A/G ratio). The urine samples were examined qualitatively for color, appearance, specific gravity, $\mathrm{pH}$, protein, glucose, ketone, bilirubin, urobilinogen, nitrite, occult blood, and leucocytes, and microscopically for epithelial cells, crystals, casts, and any other abnormal constituents.

\section{Necropsy, Organ Weight and Histopathology}

On completion of the treatment, necropsies of rats were performed. Organs (Adrenals, Brain, Ovaries, Heart, Uterus, Liver, Spleen, Kidneys, Testes, Epididymis, Thymus) were isolated and weighed for absolute and relative weights. The organs were preserved, fixed, and stained (Haematoxylin and Eosin) for histopathological evaluation via light microscopy using Olympus Trinocular Microscope with LED projector (CX-43/7F46721). Histopathological examination was conducted on brain (cerebrum, cerebellum, midbrain), spinal cord, eyes, pituitary, thyroid, parathyroid, spleen, thymus, adrenals, pancreas, trachea (at least 2 levels including 1 longitudinal section through the carina and 1 transverse section), lungs (all lobes at one level, including main bronchi), larynx (3 levels inlcuining one level for the base of the epiglottis), heart, aorta, esophagus, stomach, duodenum, jejunum, terminal ileum (with peyer's patch), colon, rectum, liver, kidneys, urinary bladder, prostate, seminal vesicle, epididymis, testes, ovaries, uterus with cervix, vagina, skin, sciatic nerve, bone marrow (smear), mammary gland (females), mesenteric lymph node, axillary lymph node, salivary gland, mandibular lymph node, nasal passage at 4 levels (including a level to include the nasopharyngeal duct and the nasal associated lymphoid tissue) including all macroscopically 
abnormal tissues and specifically nasal passage of all rats from groups G1 (VC) and G4 (IND02-NS-100).

\section{Statistical analysis}

The data and parameter values were represented as the mean \pm standard deviation (SD) and analyzed using statistical methods. Data of each parameter was analyzed by one-way ANOVA followed by Dunnett's test and Student's t-test to compare the difference between treated and control groups. The statistical analysis was performed using the SPSS version 23.0 analysis program (SPSS Inc, Chicago, Illinois, USA). Statistical significance at $\mathrm{p}<0.05$ was considered significant.

\section{RESULTS}

\section{Acute intranasal toxicity (AINT) study}

The acute study at an intranasal dose of $100 \mu \mathrm{g} / \mathrm{rat} /$ day did not reveal any mortality and abnormal clinical signs in rats. No significant body weight gain was observed during the 14-day observation post-dosing period in rats. Gross pathology findings and macroscopic examination of rats sacrificed at the termination of the study revealed no abnormalities attributable to the treatment. Therefore, the maximum tolerated dose (MTD) of intranasal IND02-NS on rats for both sexes was considered more than $100 \mu \mathrm{g} / \mathrm{rat} /$ day during the present acute toxicity study

\section{Subacute (28-day repeated dose) intranasal toxicity study}

All rats from VC and all treatment groups survived the dosing period of 28 days and the post-dosing reversal period. No signs of clinical toxicity were observed in any of the groups of rats during the entire study period and the 14 days of reversal period. Functional observation tests conducted on rats in week 4 revealed no abnormalities attributable to the treatment. Necropsy did not reveal any abnormality attributable to the treatment. The gain in body weights in male and female rats from IND02-NS-20, IND02-NS-50 and IND02-NS-100 groups was insignificant compared to VC (Table 1).

The quantity of food consumed by rats from different dose groups showed no significant difference compared to the VC group during the 28 consecutive days dosing period and the post-dosing reversal period.

\section{Buried food test}

The buried food test showed no significant change in time latency to discover food as compared to the VC group, revealing that the ability to smell volatile odors was not affected during the treatment and reversal period (Table 2).

\section{Laboratory evaluations}

The values of hematological parameters viz. hemoglobin, packed cell volume, total RBC count, total and differential WBC counts, RBC indices, platelet count, reticulocyte count, activated partial thromboplastin time, prothrombin time, and the morphology of blood cells of male and female rats, in IND02-NS group did not reveal any significant difference on the end of the treatment (day 29) or reversal period (day 43). A statistically significant increase $(\mathrm{p}<0.05)$ in prothrombin time in high dose (G4) males and an increase in eosinophil percentage in mid-dose (G3) females were observed. A mild increase in prothrombin time in the G4 group in males as compared to that of VC was recorded. However, no dose-related relationship in increased prothrombin time was observed. Furthermore, the changes from baseline were reversible on day 43 and appeared to be incidental with no biological significance.
The percent eosinophils in the G3 group in females was significantly more as compared to the respective VC group. However, the values were within the historical control range (1.824 to 4.222) and considered non-significant for toxicological significance (Tables 3 and 4).

The group means values of blood biochemistry parameters viz. total protein, albumin, globulin, alanine aminotransferase (ALT), aspartate aminotransferase (AST), alkaline phosphatase (ALP), glucose, blood urea nitrogen (BUN), urea (calculated value from urea nitrogen), creatinine, cholesterol, gamma-glutamyl transferase (GGT), total bile acid, triglyceride, total bilirubin, sodium $(\mathrm{Na})$, potassium $(\mathrm{K})$, calcium $(\mathrm{Ca})$ phosphorus $(\mathrm{P})$, albumin to globulin ratio (A/G ratio) of IND02-NS treated groups did not show the difference as compared with respective VC group at the end of treatment or the reversal period. Although, a statistically significant decrease was observed in BUN and urea (in G3 and G4 as compared respective VC groups in males (but not in females) with all values within the historical control ranges of 14 to $25 \mathrm{mg} / \mathrm{dL}$ and 20.9 to 41.2 , respectively (Tables 5 and 6).

The data on urinalysis, evaluated on day 26 of the treatment period and during the reversal period on day 41 , did not indicate any abnormal values. The values of qualitative and semi-quantitative urine parameters did not have differences between any of IND02-NS treated groups versus respective VC groups.

\section{Organ weights and Histopathology}

The values of absolute organ weights and the relative organ weights of adrenals, testes, ovaries, kidneys, liver, brain, thymus, spleen, heart, and uterus of rats treated with IND02-NS did not show significant differences as compared to the respective VC group (Tables 7 and 8).

The gross pathological findings (unilateral, undersized, underweight testes, and epididymis) were observed in the low dose (G3) treated male sacrificed on day 29. However, these findings did not have dose-dependency and were not considered to be treatment-related. All other organs examined during necropsy conducted at the end of the treatment period and reversal period did not show any gross pathological alterations in any of the male and female rats treatment groups as compared to VC groups (Table 9).

The photomicrographs of representative sections of nasal mucosa are presented in Figure 1.

There were no significant histological changes in nasal mucosa except incidental and Minimal goblet cell hyperplasia (observed in respiratory epithelium lining of the nasal septum, especially at level 1 and level 2 of the nasal passage) was found. This finding is the expected pharmacological effect as an adaptive response to any nasal exposure via production and release of an increased amount of protective substances and was not considered toxicological importance ${ }^{38}$. The microscopic examination of tissues revealed lymphoid cell infiltration in lungs, inflammatory cell infiltration in the myocardium in the heart, lymphoid cell infiltration in the liver; interstitial lymphoid cell infiltration in kidneys; corticular vacuolation and capsular cyst in adrenals, retinal rosettes, and retinal folds in eyes cysts in the pituitary; lymphoid hyperplasia in jejunum and rectum; lymphoid hyperplasia and plasmacytosis in mandibular lymph node; glandular dilation and cysts in glandular stomach lymphoid cell infiltration in prostate and epididymis, cystic glands in the thyroid, cyst in the thymus; intramuscular lymphoid cell infiltration in abdominal skin; epithelial vacuolation in the uterus; glandular dilation in trachea; lymphoid atrophy in the spleen. These changes were of minimal to mild severity, found in all treatment (including VC) groups, and not considered significant or treatment-related. 


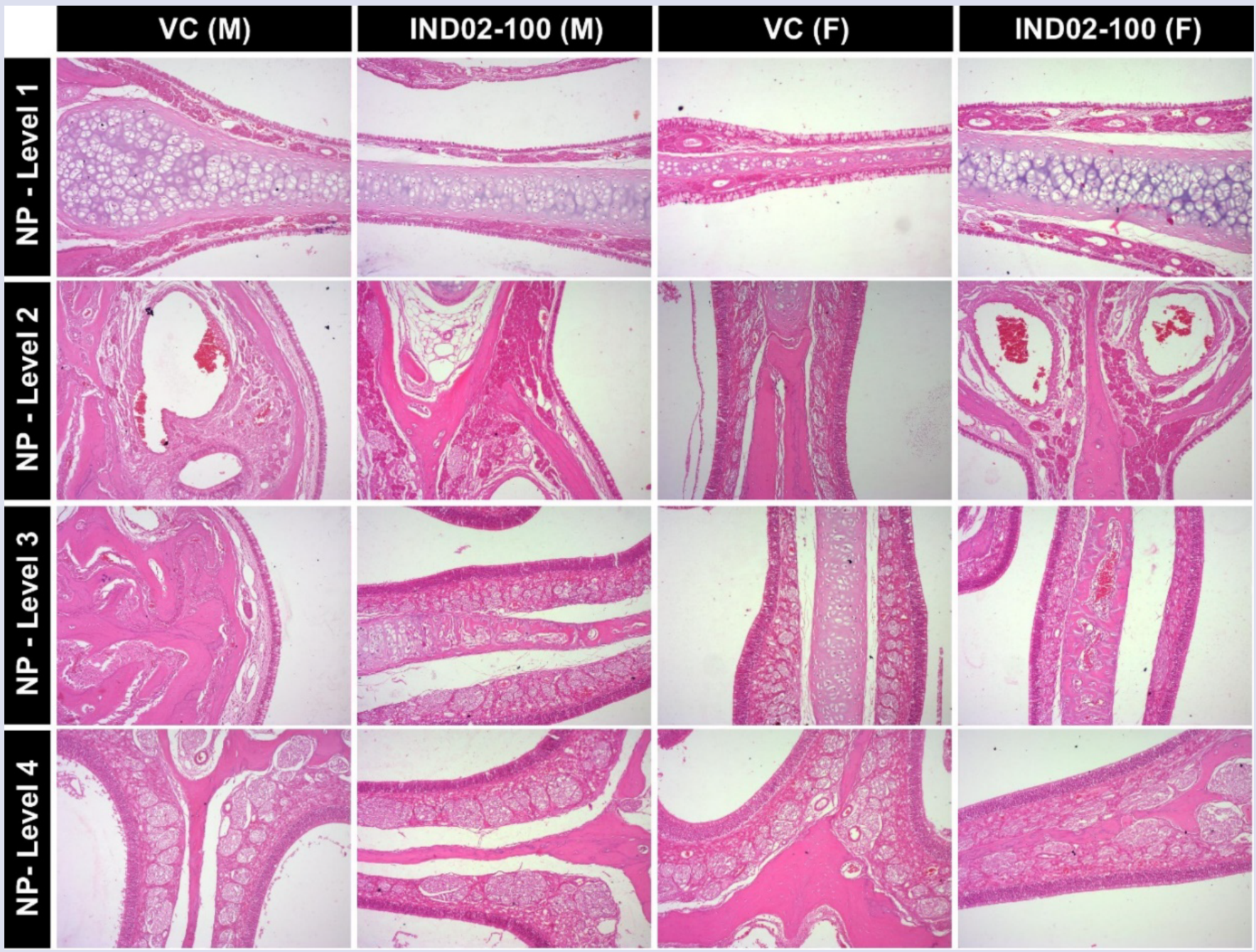

Figure 1: Photomicrograph of representative sections of nasal passage of rats at level 1 to level 4 in rats during 90-day repeated dose nasal toxicity study. (H\&E, x40), NP - Nasal Passage, M- Male, F- Female, VC-Vehicle control (G1), IND02-NS-100 (G4).

Table 1. Body weight gains $(\mathbf{g})$ of rats during 28 days repeated dose intranasal toxicity study.

\begin{tabular}{|c|c|c|c|c|c|c|}
\hline \multirow{2}{*}{ Weeks } & \multicolumn{6}{|c|}{ Group } \\
\hline & VC & IND02-20 & IND02-50 & IND02-100 & VC-R & IND02-100-R \\
\hline \multicolumn{7}{|l|}{ Male } \\
\hline 1 & $22.39 \pm 2.08$ & $21.76 \pm 2.90$ & $18.43 \pm 10.66$ & $24.23 \pm 2.63$ & $22.45 \pm 3.60$ & $21.78 \pm 2.41$ \\
\hline 2 & $15.70 \pm 1.96$ & $13.45 \pm 3.04$ & $13.07 \pm 3.62$ & $15.34 \pm 2.17$ & $14.85 \pm 2.92$ & $13.89 \pm 2.53$ \\
\hline 3 & $10.39 \pm 2.06$ & $9.70 \pm 1.68$ & $9.14 \pm 2.89$ & $11.26 \pm 2.11$ & $10.48 \pm 1.10$ & $8.07 \pm 1.89$ \\
\hline 4 & $6.32 \pm 0.64$ & $7.36 \pm 2.36$ & $6.44 \pm 2.72$ & $6.95 \pm 1.12$ & $7.93 \pm 1.91$ & $7.81 \pm 1.40$ \\
\hline 5 & - & - & - & - & $5.98 \pm 0.78$ & $4.17 \pm 1.48$ \\
\hline 6 & - & - & - & - & $6.94 \pm 2.36$ & $6.74 \pm 1.95$ \\
\hline \multicolumn{7}{|l|}{ Female } \\
\hline 1 & $12.07 \pm 3.03$ & $14.21 \pm 1.43$ & $12.95 \pm 5.11$ & $13.63 \pm 3.99$ & $11.69 \pm 3.27$ & $11.99 \pm 2.51$ \\
\hline 2 & $5.25 \pm 1.60$ & $7.25 \pm 0.92$ & $7.63 \pm 1.74$ & $6.70 \pm 1.56$ & $6.31 \pm 4.05$ & $6.85 \pm 1.35$ \\
\hline 3 & $6.54 \pm 1.85$ & $5.70 \pm 1.56$ & $6.19 \pm 1.38$ & $8.73 \pm 4.18$ & $6.40 \pm 2.67$ & $5.82 \pm 2.57$ \\
\hline 4 & $3.31 \pm 1.80$ & $6.01 \pm 1.42$ & $4.45 \pm 1.57$ & $4.91 \pm 2.40$ & $3.85 \pm 2.27$ & $4.71 \pm 1.31$ \\
\hline 5 & - & - & - & - & $2.96 \pm 2.12$ & $3.00 \pm 1.14$ \\
\hline 6 & - & - & - & - & $6.63 \pm 7.56$ & $2.79 \pm 1.17$ \\
\hline
\end{tabular}

Data was represented as Mean \pm Standard Deviation (SD). Data on all parameters were evaluated by One way ANOVA followed by Dunnett's test. Comparisons with respective days are as follows: IND02-20, IND02-50, and IND02-100 V/s. VC; IND02-100-R V/s. VC-R, n=5/sex. 
Table 2. Time to find buried food (minutes) in rats during $\mathbf{2 8}$ days repeated dose intranasal toxicity study.

\begin{tabular}{|c|c|c|c|c|c|c|}
\hline \multirow{2}{*}{ Day } & \multicolumn{6}{|c|}{ Group } \\
\hline & VC & IND02-20 & IND02-50 & IND02-100 & VC-R & IND02-100-R \\
\hline \multicolumn{7}{|l|}{ Male } \\
\hline 0 & $2.8 \pm 4.76$ & $3.6 \pm 2.70$ & $2.4 \pm 3.71$ & $2.6 \pm 1.14$ & $2.4 \pm 2.30$ & $4.0 \pm 4.12$ \\
\hline 8 & $2.0 \pm 1.00$ & $3.8 \pm 5.22$ & $5.4 \pm 4.04$ & $1.6 \pm 0.89$ & $6.0 \pm 5.57$ & $2.8 \pm 1.30$ \\
\hline 15 & $3.4 \pm 3.71$ & $4.8 \pm 3.35$ & $6.6 \pm 5.77$ & $3.6 \pm 4.72$ & $5.2 \pm 5.22$ & $6.4 \pm 3.36$ \\
\hline 22 & $6.2 \pm 5.59$ & $5.0 \pm 2.83$ & $7.2 \pm 5.76$ & $2.2 \pm 1.30$ & $5.0 \pm 4.30$ & $7.0 \pm 4.74$ \\
\hline 29 & $1.4 \pm 0.89$ & $4.8 \pm 4.49$ & $4.6 \pm 5.13$ & $3.2 \pm 4.92$ & $3.8 \pm 3.63$ & $8.6 \pm 6.50$ \\
\hline 36 & - & - & - & - & $3.2 \pm 4.92$ & $4.0 \pm 3.32$ \\
\hline 43 & - & - & - & - & $4.8 \pm 4.97$ & $8.0 \pm 7.04$ \\
\hline \multicolumn{7}{|c|}{ Female } \\
\hline 0 & $2.6 \pm 3.58$ & $2.8 \pm 3.03$ & $3.0 \pm 3.94$ & $1.2 \pm 0.45$ & $2.4 \pm 1.67$ & $1.8 \pm 0.84$ \\
\hline 8 & $4.4 \pm 4.16$ & $1.2 \pm 0.45$ & $3.6 \pm 3.21$ & $1.6 \pm 0.89$ & $2.0 \pm 1.73$ & $2.4 \pm 1.95$ \\
\hline 15 & $2.4 \pm 2.61$ & $1.0 \pm 0.00$ & $4.0 \pm 2.55$ & $3.0 \pm 2.83$ & $2.6 \pm 1.52$ & $2.4 \pm 1.95$ \\
\hline 22 & $5.6 \pm 4.83$ & $1.6 \pm 1.34$ & $3.6 \pm 4.22$ & $3.2 \pm 3.83$ & $3.0 \pm 3.08$ & $2.4 \pm 2.19$ \\
\hline 29 & $1.2 \pm 0.45$ & $1.6 \pm 0.89$ & $2.6 \pm 2.07$ & $1.8 \pm 0.84$ & $3.0 \pm 2.35$ & $3.0 \pm 3.08$ \\
\hline 36 & - & - & - & - & $1.2 \pm 0.45$ & $1.0 \pm 0.00$ \\
\hline 43 & - & - & - & - & $3.0 \pm 2.00$ & $2.4 \pm 3.21$ \\
\hline
\end{tabular}

Data was represented as Mean \pm Standard Deviation (SD). Data on all parameters were evaluated by One way ANOVA followed by Dunnett's test. Comparisons with respective days are as follows: IND02-20, IND02-50, and IND02-100 V/s. VC; IND02-100-R V/s. VC-R, n= 5/sex.

Table 3. Hematological parameters during 28 days repeated dose intranasal toxicity study (Male rats).

\begin{tabular}{|c|c|c|c|c|c|c|}
\hline \multirow{2}{*}{ Parameters } & \multicolumn{6}{|c|}{ Group } \\
\hline & VC & IND02-20 & IND02-50 & IND02-100 & VC-R & IND02-100-R \\
\hline $\mathrm{Hb}(\mathrm{g} / \mathrm{dl})$ & $16.50 \pm 0.32$ & $16.12 \pm 0.33$ & $16.20 \pm 0.45$ & $15.84 \pm 0.82$ & $15.88 \pm 0.68$ & $15.80 \pm 0.46$ \\
\hline PCV (\%) & $47.48 \pm 1.03$ & $46.70 \pm 0.71$ & $45.74 \pm 1.09$ & $45.76 \pm 2.78$ & $46.16 \pm 2.27$ & $45.32 \pm 1.56$ \\
\hline $\mathrm{RBC}(\mathrm{x} 106 / \mathrm{cmm})$ & $8.58 \pm 0.26$ & $8.49 \pm 0.23$ & $8.74 \pm 0.41$ & $8.27 \pm 0.51$ & $8.31 \pm 0.46$ & $8.60 \pm 0.31$ \\
\hline $\mathrm{MCH}(\mathrm{pg})$ & $19.28 \pm 0.69$ & $19.00 \pm 0.35$ & $18.56 \pm 0.44$ & $18.88 \pm 0.61$ & $19.18 \pm 0.96$ & $18.38 \pm 0.48$ \\
\hline $\operatorname{MCV}(f l)$ & $55.42 \pm 2.46$ & $55.08 \pm 0.91$ & $53.88 \pm 0.88$ & $54.54 \pm 1.34$ & $55.6 \pm 2.55$ & $52.68 \pm 1.18$ \\
\hline $\mathrm{MCHC}(\mathrm{g} / \mathrm{dl})$ & $34.80 \pm 0.48$ & $34.54 \pm 0.54$ & $34.54 \pm 0.30$ & $34.60 \pm 0.60$ & $34.46 \pm 0.44$ & $34.90 \pm 0.25$ \\
\hline \multirow[t]{2}{*}{ TLC (x $103 / \mathrm{cmm})$} & $4.60 \pm 0.60$ & $4.25 \pm 1.21$ & $4.13 \pm 0.78$ & $5.07 \pm 3.06$ & $4.92 \pm 0.48$ & $4.53 \pm 1.15$ \\
\hline & & & DLC & & & \\
\hline N (\%) & $27.70 \pm 6.10$ & $33.06 \pm 8.49$ & $26.56 \pm 4.90$ & $31.72 \pm 13.20$ & $26.08 \pm 5.29$ & $27.20 \pm 5.42$ \\
\hline $\mathrm{L}(\%)$ & $69.14 \pm 5.49$ & $63.92 \pm 7.38$ & $70.16 \pm 4.96$ & $64.68 \pm 12.73$ & $71.10 \pm 5.16$ & $69.48 \pm 5.37$ \\
\hline M (\%) & $0.722 \pm 0.374$ & $0.504 \pm 0.178$ & $0.765 \pm 0.407$ & $0.729 \pm 0.625$ & $0.500 \pm 0.285$ & $0.834 \pm 0.310$ \\
\hline E (\%) & $2.444 \pm 0.982$ & $2.516 \pm 1.154$ & $2.494 \pm 0.829$ & $2.848 \pm 0.421$ & $2.296 \pm 0.966$ & $2.440 \pm 0.550$ \\
\hline B (\%) & $0.005 \pm 0.011$ & $0.024 \pm 0.042$ & $0.024 \pm 0.053$ & $0.005 \pm 0.010$ & $0.015 \pm 0.014$ & $0.028 \pm 0.052$ \\
\hline Platelets (x $103 / \mathrm{cmm}$ ) & $749.0 \pm 146.05$ & $693.2 \pm 303.98$ & $658.4 \pm 262.58$ & $694.0 \pm 267.84$ & $624.0 \pm 250.77$ & $714.4 \pm 121.22$ \\
\hline Reticulocytes (\%) & $2.49 \pm 0.47$ & $1.94 \pm 0.55$ & $1.94 \pm 0.57$ & $2.45 \pm 0.20$ & $3.10 \pm 0.80$ & $2.71 \pm 0.34$ \\
\hline APTT (sec) & $15.72 \pm 2.33$ & $16.84 \pm 3.47$ & $15.78 \pm 3.28$ & $16.12 \pm 1.24$ & $12.82 \pm 2.75$ & $16.46 \pm 0.46$ \\
\hline PT (sec) & $15.68 \pm 0.92$ & $16.74 \pm 1.04$ & $17.08 \pm 1.97$ & $19.44 \pm 1.18^{*}$ & $15.92 \pm 0.91$ & $16.80 \pm 1.05$ \\
\hline
\end{tabular}

Data was represented as Mean \pm Standard Deviation (SD). Data on all parameters were evaluated by One way ANOVA followed by Dunnett's test. * $\mathrm{P}<0.05$ Comparisons with respective days are as follows: IND02-20, IND02-50, and IND02-100 V/s. VC; IND02-100-R V/s. VC-R, n= 5/sex. Hb: Hemoglobin; PCV: Packed Cell Volume, RBC: Red Blood Corpuscles, MCH: Mean Corpuscular Hemoglobin, MCV: Mean Corpuscular Volume, MCHC: Mean Corpuscular Hemoglobin Concentration, TLC:Total leukocyte (White Blood Corpuscles) count, N: Neutrophils, L: Lymphocytes, M : Monocytes, E: Eosinophils, B : Basophils, APTT: Activated Partial Thromboplastin Time, PT.: Prothrombin time.

\section{DISCUSSION}

Worldwide, the prevalence of allergic diseases has continued to increase in the industrialized world. AR is an inflammatory disorder of the nasal mucosa initiated by an allergic immune response to inhaled allergens in sensitized individuals. AR affects $10 \%$ to $30 \%$ of the population worldwide ${ }^{39}$. AR disrupts the upper airway's normal function, causing considerable disability, co-morbidities, and loss of quality of life (QoL). Any treatment of AR is expected to restore and enable the patient to achieve normal social function, olfaction, taste, and restful and peaceful sleep. Control of AR is of paramount importance for QoL issues to decrease the severity of co-morbidities associated with AR. A decreased QoL associated with AR is often associated with post-nasal drip, red, itchy, watery eyes, headaches, facial discomfort, and ear discomfort ${ }^{40}$.
There are various types of treatments available such as antihistamines, intranasal steroids, immunotherapies, and complementary medicines. Intranasal steroids provide significant relief of symptoms and are the most effective medication class in controlling the symptoms of AR. However, intranasal steroids were reported a few incidences of adverse effects such as epistaxis, headache, abnormal taste, and pharyngitis ${ }^{41}$. Therefore, safety evaluations for nasal compounds using international guidelines are crucial before products are marketed for human use.

In the present study, the acute and 28-days sub-acute toxicity of IND02NS was evaluated in rats using the intranasal route of administration. IND02-NS did not show any treatment-related changes in body weight gain, food consumption, ability to smell volatile odors by buried food test, hematological biochemical and histological parameters 
Table 4. Hematological parameters during 28 days repeated dose intranasal toxicity study (Female rats).

\begin{tabular}{|c|c|c|c|c|c|c|}
\hline \multirow{2}{*}{ Parameters } & \multicolumn{6}{|c|}{ Group } \\
\hline & VC & IND02-20 & IND02-50 & IND02-100 & VC-R & IND02-100-R \\
\hline $\mathrm{Hb}(\mathrm{g} / \mathrm{dl})$ & $15.34 \pm 0.58$ & $15.16 \pm 0.60$ & $15.06 \pm 0.44$ & $14.74 \pm 0.87$ & $15.2 \pm 0.59$ & $15.16 \pm 0.79$ \\
\hline PCV (\%) & $43.82 \pm 1.79$ & $43.18 \pm 2.12$ & $43.28 \pm 1.47$ & $42.16 \pm 2.51$ & $44.04 \pm 1.82$ & $43.76 \pm 2.25$ \\
\hline $\mathrm{RBC}(\mathrm{x} 106 / \mathrm{cmm})$ & $7.89 \pm 0.32$ & $7.84 \pm 0.43$ & $7.95 \pm 0.20$ & $7.59 \pm 0.69$ & $8.32 \pm 0.38$ & $8.19 \pm 0.51$ \\
\hline $\mathrm{MCH}(\mathrm{pg})$ & $19.40 \pm 0.41$ & $19.34 \pm 0.45$ & $18.92 \pm 0.30$ & $19.48 \pm 0.79$ & $18.26 \pm 0.55$ & $18.56 \pm 0.93$ \\
\hline $\operatorname{MCV}(\mathrm{fl})$ & $55.44 \pm 1.58$ & $55.12 \pm 1.26$ & $54.40 \pm 0.79$ & $55.66 \pm 2.26$ & $52.96 \pm 1.57$ & $53.50 \pm 2.57$ \\
\hline $\mathrm{MCHC}(\mathrm{g} / \mathrm{dl})$ & $35.02 \pm 0.43$ & $35.1 \pm 0.44$ & $34.78 \pm 0.46$ & $34.98 \pm 0.29$ & $34.52 \pm 0.18$ & $34.68 \pm 0.23$ \\
\hline \multirow[t]{2}{*}{ TLC (x $103 / \mathrm{cmm})$} & $3.26 \pm 0.80$ & $3.43 \pm 1.25$ & $3.45 \pm 0.71$ & $3.41 \pm 0.70$ & $2.88 \pm 0.85$ & $2.71 \pm 1.16$ \\
\hline & & & DLC & & & \\
\hline N (\%) & $21.78 \pm 7.56$ & $35.46 \pm 13.47$ & $27.62 \pm 9.31$ & $22.66 \pm 4.82$ & $21.2 \pm 3.20$ & $19.14 \pm 6.04$ \\
\hline L (\%) & $75.74 \pm 7.28$ & $61.00 \pm 13.54$ & $67.66 \pm 8.42$ & $74.16 \pm 4.58$ & $76.02 \pm 4.00$ & $77.10 \pm 6.20$ \\
\hline M (\%) & $0.492 \pm 0.177$ & $0.899 \pm 0.490$ & $1.492 \pm 1.626$ & $0.901 \pm 1.066$ & $0.717 \pm 0.476$ & $0.754 \pm 0.356$ \\
\hline E (\%) & $1.990 \pm 0.390$ & $2.624 \pm 0.518$ & $3.158 \pm 0.924^{*}$ & $2.292 \pm 0.335$ & $1.916 \pm 0.547$ & $2.902 \pm 0.613$ \\
\hline B (\%) & $0.000 \pm 0.000$ & $0.022 \pm 0.031$ & $0.045 \pm 0.072$ & $0.000 \pm 0.000$ & $0.122 \pm 0.211$ & $0.072 \pm 0.088$ \\
\hline Platelets (x $103 / \mathrm{cmm}$ ) & $832.20 \pm 74.40$ & $902.20 \pm 97.70$ & $811.40 \pm 154.93$ & $846.20 \pm 126.55$ & $479.60 \pm 300.05$ & $637.20 \pm 352.40$ \\
\hline Reticulocytes (\%) & $2.91 \pm 0.96$ & $2.92 \pm 0.46$ & $3.94 \pm 1.98$ & $3.71 \pm 0.95$ & $2.74 \pm 0.95$ & $2.70 \pm 0.44$ \\
\hline $\operatorname{APTT}(\mathrm{sec})$ & $18.88 \pm 1.69$ & $16.70 \pm 3.99$ & $15.18 \pm 2.34$ & $15.20 \pm 2.29$ & $13.24 \pm 1.21$ & $15.18 \pm 1.55$ \\
\hline PT (sec) & $15.62 \pm 1.32$ & $15.38 \pm 1.75$ & $15.24 \pm 1.11$ & $16.68 \pm 1.64$ & $15.44 \pm 3.16$ & $19.46 \pm 0.95$ \\
\hline
\end{tabular}

Data was represented as Mean \pm Standard Deviation (SD). Data on all parameters were evaluated by One way ANOVA followed by Dunnett's test. * $P<0.05$ Comparisons with respective days are as follows: IND02-20, IND02-50, and IND02-100 V/s. VC; IND02-100-R V/s. VC-R, n= 5/sex. Hb: Hemoglobin; PCV: Packed Cell Volume, RBC: Red Blood Corpuscles, MCH: Mean Corpuscular Hemoglobin, MCV: Mean Corpuscular Volume, MCHC: Mean Corpuscular Hemoglobin Concentration, TLC: Total leukocyte (White Blood Corpuscles) count, N: Neutrophils, L: Lymphocytes, M : Monocytes, E: Eosinophils, B : Basophils, APTT: Activated Partial Thromboplastin Time, PT.: Prothrombin time.

Table 5. Blood biochemistry during 28 days repeated dose intranasal toxicity study (male rats).

\begin{tabular}{|c|c|c|c|c|c|c|}
\hline \multirow{2}{*}{ Parameters } & \multicolumn{6}{|c|}{ Group } \\
\hline & VC & IND02-20 & IND02-50 & IND02-100 & VC-R & IND02-100-R \\
\hline Total Protein $(\mathrm{g} / \mathrm{dL})$ & $7.20 \pm 0.34$ & $7.24 \pm 0.19$ & $7.02 \pm 0.18$ & $6.96 \pm 0.19$ & $6.86 \pm 0.26$ & $6.90 \pm 0.22$ \\
\hline Albumin (g/dL) & $1.30 \pm 0.16$ & $1.30 \pm 0.10$ & $1.38 \pm 0.04$ & $1.30 \pm 0.07$ & $1.30 \pm 0.07$ & $1.34 \pm 0.09$ \\
\hline Globulin (g/dL) & $5.90 \pm 0.27$ & $5.94 \pm 0.11$ & $5.64 \pm 0.18$ & $5.66 \pm 0.21$ & $5.56 \pm 0.23$ & $5.56 \pm 0.22$ \\
\hline ALT(IU/L) & $37.60 \pm 7.92$ & $41.40 \pm 10.64$ & $33.40 \pm 3.78$ & $30.80 \pm 3.83$ & $36.80 \pm 6.91$ & $31.00 \pm 4.06$ \\
\hline AST (IU/L) & $87.00 \pm 12.41$ & $87.40 \pm 3.36$ & $83.20 \pm 17.24$ & $79.80 \pm 4.09$ & $78.20 \pm 12.54$ & $80.40 \pm 13.54$ \\
\hline ALP (IU/L) & $135.00 \pm 12.41$ & $123.00 \pm 17.01$ & $130.80 \pm 21.03$ & $134.80 \pm 25.07$ & $118.60 \pm 26.33$ & $104.00 \pm 10.32$ \\
\hline Glucose (mg/dL) & $95.60 \pm 10.16$ & $92.40 \pm 9.21$ & $83.20 \pm 6.18$ & $98.20 \pm 8.67$ & $99.80 \pm 6.76$ & $104.60 \pm 4.98$ \\
\hline BUN (mg/dL) & $22.60 \pm 3.85$ & $19.40 \pm 0.89$ & $17.00 \pm 1.22^{\star}$ & $17.00 \pm 2.35^{\star}$ & $25.40 \pm 3.21$ & $20.80 \pm 2.05$ \\
\hline Urea (mg/dL) & $48.36 \pm 8.23$ & $41.52 \pm 1.91$ & $36.38 \pm 2.62^{*}$ & $36.38 \pm 5.02^{*}$ & $54.36 \pm 6.87$ & $44.51 \pm 4.39$ \\
\hline Creatinine (mg/dL) & $0.50 \pm 0.06$ & $0.46 \pm 0.07$ & $0.43 \pm 0.04$ & $0.47 \pm 0.08$ & $0.49 \pm 0.03$ & $0.51 \pm 0.04$ \\
\hline Cholesterol (mg/dL) & $58.00 \pm 11.07$ & $62.80 \pm 5.76$ & $65.20 \pm 13.83$ & $59.00 \pm 7.31$ & $60.00 \pm 4.18$ & $52.60 \pm 5.46$ \\
\hline GGT (IU/L) & $6.20 \pm 0.45$ & $6.20 \pm 0.84$ & $6.20 \pm 0.84$ & $5.80 \pm 0.45$ & $5.400 \pm 1.14$ & $5.20 \pm 0.45$ \\
\hline $\begin{array}{l}\text { Total bile acid } \\
(\mu \mathrm{mol} / \mathrm{L})\end{array}$ & $26.31 \pm 13.65$ & $14.15 \pm 5.13$ & $27.73 \pm 11.3$ & $28.93 \pm 3.43$ & $37.50 \pm 20.8$ & $19.29 \pm 8.44$ \\
\hline Triglyceride (mg/dL) & $70.60 \pm 12.70$ & $85.00 \pm 28.45$ & $84.00 \pm 9.87$ & $65.40 \pm 14.98$ & $72.60 \pm 25.9$ & $60.00 \pm 8.83$ \\
\hline $\begin{array}{l}\text { Total Bilirubin (mg/ } \\
\text { dL) }\end{array}$ & $0.12 \pm 0.04$ & $0.16 \pm 0.05$ & $0.10 \pm 0.00$ & $0.10 \pm 0.00$ & $0.14 \pm 0.05$ & $0.10 \pm 0.00$ \\
\hline $\mathrm{Na}(\mathrm{mmol} / \mathrm{l})$ & $148.60 \pm 1.14$ & $148.20 \pm 0.84$ & $148.00 \pm 1.41$ & $146.60 \pm 0.89$ & $144.20 \pm 0.84$ & $144.60 \pm 1.14$ \\
\hline $\mathrm{K}(\mathrm{mmol} / \mathrm{l})$ & $5.04 \pm 0.22$ & $5.16 \pm 0.19$ & $5.02 \pm 0.16$ & $4.96 \pm 0.53$ & $5.00 \pm 0.31$ & $5.00 \pm 0.46$ \\
\hline $\mathrm{CA}(\mathrm{mg} / \mathrm{dL})$ & $10.34 \pm 0.24$ & $10.20 \pm 0.22$ & $10.70 \pm 0.23$ & $10.38 \pm 0.64$ & $10.10 \pm 0.32$ & $10.38 \pm 0.13$ \\
\hline $\mathrm{P}(\mathrm{mg} / \mathrm{dL})$ & $7.26 \pm 0.67$ & $6.72 \pm 0.59$ & $6.96 \pm 0.21$ & $7.54 \pm 0.87$ & $6.50 \pm 0.46$ & $6.16 \pm 0.7$ \\
\hline $\mathrm{A} / \mathrm{G}$ ratio $(\mathrm{g} / \mathrm{dL})$ & $0.22 \pm 0.03$ & $0.22 \pm 0.01$ & $0.24 \pm 0.01$ & $0.23 \pm 0.02$ & $0.23 \pm 0.01$ & $0.24 \pm 0.02$ \\
\hline
\end{tabular}

Data was represented as Mean \pm Standard Deviation (SD). Data on all parameters were evaluated by One way ANOVA followed by Dunnett's test. * $P<0.05$ Comparisons with respective days are as follows: IND02-20, IND02-50, and IND02-100 V/s. VC; IND02-100-R V/s. VC-R, n= 5/sex. ALT: Alanine Aminotransferase, AST: Aspartate Aminotransferase, ALP: Alkaline Phosphatase, BUN: Blood Urea Nitrogen, GGT: Gamma Glutamyl Transferase, Na: Sodium, K: Potassium, CA: Calcium, P: Phosphorus, $\mathrm{A} / \mathrm{G}$ ratio: Albumin to Globulin ratio. 
Table 6. Blood biochemistry during 28 days repeated dose intranasal toxicity study (Female rats).

\begin{tabular}{|c|c|c|c|c|c|c|}
\hline \multirow{2}{*}{ Parameters } & \multicolumn{6}{|c|}{ Group } \\
\hline & VC & IND02-20 & IND02-50 & IND02-100 & VC-R & IND02-100-R \\
\hline Total Protein (g/dL) & $7.38 \pm 0.28$ & $7.3 \pm 0.34$ & $7.46 \pm 0.21$ & $7.28 \pm 0.30$ & $7.60 \pm 1.42$ & $7.00 \pm 0.91$ \\
\hline Albumin $(\mathrm{g} / \mathrm{dL})$ & $1.48 \pm 0.08$ & $1.46 \pm 0.15$ & $1.40 \pm 0.00$ & $1.40 \pm 0.10$ & $1.50 \pm 0.23$ & $1.32 \pm 0.28$ \\
\hline Globulin (g/dL) & $5.90 \pm 0.21$ & $5.84 \pm 0.24$ & $6.06 \pm 0.21$ & $5.88 \pm 0.29$ & $6.10 \pm 1.19$ & $5.68 \pm 0.77$ \\
\hline ALT(IU/L) & $23.20 \pm 5.63$ & $23.40 \pm 4.16$ & $25.00 \pm 4.12$ & $23.40 \pm 5.41$ & $25.80 \pm 8.87$ & $28.20 \pm 9.68$ \\
\hline AST (IU/L) & $77.20 \pm 10.06$ & $79.00 \pm 14.51$ & $86.40 \pm 20.61$ & $79.20 \pm 9.68$ & $85.20 \pm 14.84$ & $128.20 \pm 74.51$ \\
\hline ALP (IU/L) & $60.00 \pm 8.4$ & $71.60 \pm 5.41$ & $72.00 \pm 12.79$ & $62.60 \pm 12.88$ & $54.40 \pm 9.24$ & $93.60 \pm 58.29$ \\
\hline Glucose (mg/dL) & $107.60 \pm 5.32$ & $108.60 \pm 3.85$ & $101.00 \pm 6.2$ & $106.00 \pm 13.27$ & $78.40 \pm 18.12$ & $80.40 \pm 23.92$ \\
\hline BUN (mg/dL) & $21.20 \pm 2.39$ & $18.80 \pm 2.77$ & $19.20 \pm 1.3$ & $19.20 \pm 2.59$ & $21.20 \pm 2.59$ & $17.20 \pm 5.12$ \\
\hline Urea (mg/dL) & $45.37 \pm 5.11$ & $40.23 \pm 5.94$ & $41.09 \pm 2.79$ & $41.09 \pm 5.54$ & $45.37 \pm 5.54$ & $36.81 \pm 10.95$ \\
\hline Creatinine (mg/dL) & $0.46 \pm 0.05$ & $0.49 \pm 0.06$ & $0.50 \pm 0.05$ & $0.46 \pm 0.07$ & $0.58 \pm 0.14$ & $0.66 \pm 0.11$ \\
\hline Cholesterol (mg/dL) & $46.60 \pm 6.19$ & $50.6 \pm 6.02$ & $55.00 \pm 15.6$ & $55.80 \pm 9.55$ & $54.40 \pm 3.91$ & $58.00 \pm 12.63$ \\
\hline GGT (IU/L) & $5.40 \pm 1.14$ & $7.00 \pm 0.71$ & $7.20 \pm 0.45$ & $5.20 \pm 0.84$ & $5.40 \pm 0.55$ & $6.80 \pm 0.84$ \\
\hline $\begin{array}{l}\text { Total bile acid } \\
(\mu \mathrm{mol} / \mathrm{L})\end{array}$ & $22.13 \pm 13.7$ & $29.49 \pm 21.5$ & $28.70 \pm 20.17$ & $19.95 \pm 8.02$ & $16.47 \pm 10.45$ & $13.69 \pm 4.49$ \\
\hline Triglyceride (mg/dL) & $66.00 \pm 19.05$ & $46.00 \pm 6.60$ & $44.40 \pm 7.20$ & $51.80 \pm 23.24$ & $73.80 \pm 2.86$ & $49.00 \pm 20.72$ \\
\hline $\begin{array}{l}\text { Total Bilirubin (mg/ } \\
\mathrm{dL} \text { ) }\end{array}$ & $0.16 \pm 0.05$ & $0.14 \pm 0.05$ & $0.10 \pm 0.00$ & $0.14 \pm 0.05$ & $0.16 \pm 0.11$ & $0.16 \pm 0.05$ \\
\hline $\mathrm{Na}(\mathrm{mmol} / \mathrm{l})$ & $143.40 \pm 2.51$ & $142.60 \pm 0.55$ & $145.40 \pm 0.89$ & $145.00 \pm 1.73$ & $153.40 \pm 5.08$ & $154.80 \pm 11.43$ \\
\hline $\mathrm{K}(\mathrm{mmol} / \mathrm{l})$ & $5.10 \pm 0.36$ & $4.96 \pm 0.50$ & $5.28 \pm 0.31$ & $5.04 \pm 0.26$ & $5.02 \pm 0.49$ & $5.28 \pm 0.63$ \\
\hline $\mathrm{CA}(\mathrm{mg} / \mathrm{dL})$ & $10.68 \pm 0.11$ & $10.70 \pm 0.26$ & $10.92 \pm 0.2$ & $10.56 \pm 0.36$ & $11.32 \pm 0.66$ & $9.12 \pm 1.22$ \\
\hline $\mathrm{P}(\mathrm{mg} / \mathrm{dL})$ & $5.38 \pm 0.36$ & $5.52 \pm 0.51$ & $6.02 \pm 0.81$ & $5.94 \pm 0.27$ & $6.100 \pm 1.51$ & $6.50 \pm 2.66$ \\
\hline $\mathrm{A} / \mathrm{G}$ ratio $(\mathrm{g} / \mathrm{dL})$ & $0.25 \pm 0.01$ & $0.25 \pm 0.02$ & $0.23 \pm 0.01$ & $0.24 \pm 0.02$ & $0.25 \pm 0.02$ & $0.23 \pm 0.05$ \\
\hline
\end{tabular}

Data was represented as Mean \pm Standard Deviation (SD). Data on all parameters were evaluated by One way ANOVA followed by Dunnett's test. Comparisons with respective days are as follows: IND02-20, IND02-50, and IND02-100 V/s. VC; IND02-100-R V/s. VC-R, n= 5/sex. ALT: Alanine Aminotransferase, AST: Aspartate Aminotransferase, ALP: Alkaline Phosphatase, BUN: Blood Urea Nitrogen, GGT: Gamma Glutamyl Transferase, Na: Sodium, K: Potassium, CA: Calcium, P: Phosphorus, A/G ratio: Albumin to Globulin ratio.

Table 7. Relative organ weights (g) during 28-days repeated-dose intranasal toxicity study (Male rats).

\begin{tabular}{|c|c|c|c|c|c|c|}
\hline \multirow{2}{*}{ Parameters } & \multicolumn{6}{|c|}{ Group } \\
\hline & VC & IND02-20 & IND02-50 & IND02-100 & VC-R & IND02-100-R \\
\hline Adrenals & $0.016 \pm 0.003$ & $0.019 \pm 0.002$ & $0.019 \pm 0.002$ & $0.017 \pm 0.001$ & $0.017 \pm 0.002$ & $0.019 \pm 0.001$ \\
\hline Testes & $1.19 \pm 0.13$ & $1.19 \pm 0.22$ & $1.25 \pm 0.11$ & $1.11 \pm 0.03$ & $1.08 \pm 0.07$ & $1.03 \pm 0.21$ \\
\hline Kidneys & $0.78 \pm 0.10$ & $0.72 \pm 0.04$ & $0.76 \pm 0.08$ & $0.73 \pm 0.05$ & $0.65 \pm 0.01$ & $0.7 \pm 0.08$ \\
\hline Liver & $3.14 \pm 0.40$ & $3.00 \pm 0.23$ & $3.01 \pm 0.28$ & $2.95 \pm 0.29$ & $2.68 \pm 0.16$ & $2.69 \pm 0.25$ \\
\hline Brain & $0.78 \pm 0.07$ & $0.77 \pm 0.04$ & $0.78 \pm 0.09$ & $0.73 \pm 0.02$ & $0.65 \pm 0.04$ & $0.70 \pm 0.09$ \\
\hline Thymus & $0.17 \pm 0.03$ & $0.15 \pm 0.01$ & $0.16 \pm 0.04$ & $0.17 \pm 0.02$ & $0.18 \pm 0.02$ & $0.15 \pm 0.01$ \\
\hline Heart & $0.35 \pm 0.03$ & $0.32 \pm 0.01$ & $0.33 \pm 0.03$ & $0.30 \pm 0.02$ & $0.33 \pm 0.03$ & $0.34 \pm 0.02$ \\
\hline Spleen & $0.22 \pm 0.03$ & $0.23 \pm 0.05$ & $0.19 \pm 0.03$ & $0.19 \pm 0.02$ & $0.22 \pm 0.02$ & $0.22 \pm 0.03$ \\
\hline Epididymis & $0.36 \pm 0.06$ & $0.36 \pm 0.05$ & $0.37 \pm 0.07$ & $0.34 \pm 0.02$ & $0.39 \pm 0.03$ & $0.46 \pm 0.04$ \\
\hline
\end{tabular}

Data was represented as Mean \pm Standard Deviation (SD). Data on all parameters were evaluated by One way ANOVA followed by Dunnett's test. Comparisons with respective days are as follows: IND02-20, IND02-50, and IND02-100 V/s. VC; IND02-100-R V/s. VC-R, n= 5/sex.

Table 8. Relative organ weights (g) during 28-days repeated-dose intranasal toxicity study (Female rats).

\begin{tabular}{|c|c|c|c|c|c|c|}
\hline \multirow{2}{*}{ Parameters } & \multicolumn{6}{|c|}{ Group } \\
\hline & VC & IND02-20 & IND02-50 & IND02-100 & VC-R & IND02-100-R \\
\hline Adrenals & $0.038 \pm 0.005$ & $0.038 \pm 0.01$ & $0.036 \pm 0.004$ & $0.037 \pm 0.006$ & $0.032 \pm 0.003$ & $0.033 \pm 0.003$ \\
\hline Ovaries & $0.066 \pm 0.008$ & $0.071 \pm 0.007$ & $0.08 \pm 0.012$ & $0.071 \pm 0.014$ & $0.068 \pm 0.005$ & $0.071 \pm 0.021$ \\
\hline Kidneys & $0.78 \pm 0.06$ & $0.83 \pm 0.13$ & $0.85 \pm 0.14$ & $0.88 \pm 0.17$ & $0.81 \pm 0.13$ & $0.78 \pm 0.05$ \\
\hline Liver & $2.98 \pm 0.23$ & $3.17 \pm 0.27$ & $3.17 \pm 0.25$ & $3.24 \pm 0.46$ & $3.03 \pm 0.18$ & $2.98 \pm 0.30$ \\
\hline Brain & $1.11 \pm 0.06$ & $1.06 \pm 0.06$ & $1.12 \pm 0.04$ & $1.14 \pm 0.14$ & $1.01 \pm 0.07$ & $0.98 \pm 0.06$ \\
\hline Thymus & $0.28 \pm 0.03$ & $0.29 \pm 0.04$ & $0.3 \pm 0.06$ & $0.31 \pm 0.07$ & $0.22 \pm 0.02$ & $0.20 \pm 0.04$ \\
\hline Heart & $0.40 \pm 0.08$ & $0.42 \pm 0.07$ & $0.40 \pm 0.05$ & $0.37 \pm 0.05$ & $0.36 \pm 0.02$ & $0.35 \pm 0.02$ \\
\hline Spleen & $0.26 \pm 0.02$ & $0.25 \pm 0.02$ & $0.26 \pm 0.02$ & $0.28 \pm 0.05$ & $0.23 \pm 0.03$ & $0.23 \pm 0.04$ \\
\hline Uterus & $0.32 \pm 0.07$ & $0.29 \pm 0.02$ & $0.30 \pm 0.06$ & $0.34 \pm 0.06$ & $0.30 \pm 0.04$ & $0.29 \pm 0.03$ \\
\hline
\end{tabular}

Data was represented as Mean \pm Standard Deviation (SD). Data on all parameters were evaluated by One way ANOVA followed by Dunnett's test. Comparisons with respective days are as follows: IND02-20, IND02-50, and IND02-100 V/s. VC; IND02-100-R V/s. VC-R, n= 5/sex. 
Table 9. Summary of gross pathology findings.

\begin{tabular}{|c|c|c|c|c|c|c|c|c|c|c|c|c|}
\hline Group & & & & -20 & IND & -50 & IND & 100 & & & INDO & 00-R \\
\hline Dose (mg/kg) & $0 \mu \mathrm{g}$ & /day & $20 \mu$ & t/day & $50 \mu \mathrm{g}$ & t/day & $100 \mu$ & t/day & $0 \mu \mathrm{g}$ & day & $100 \mu$ & t/day \\
\hline & & & & & & & & & & & ( $\mathrm{Re}$ & \\
\hline Sex & M & $\mathrm{F}$ & M & $\mathrm{F}$ & M & $\mathrm{F}$ & M & $\mathrm{F}$ & M & $\mathrm{F}$ & $\mathrm{M}$ & $\mathrm{F}$ \\
\hline Organs/lesions & NAD & NAD & $4 / 5$ & NAD & NAD & NAD & NAD & NAD & NAD & NAD & NAD & NAD \\
\hline $\begin{array}{l}\text { Testes } \\
\text { Undersized, } \\
\text { underweight, unilateral }\end{array}$ & - & - & $1 / 5$ & - & - & - & - & - & - & - & - & - \\
\hline $\begin{array}{l}\text { Epididymis } \\
\text { Undersized, } \\
\text { underweight, unilateral }\end{array}$ & - & - & $1 / 5$ & - & - & - & - & - & - & - & - & - \\
\hline
\end{tabular}

$\mathrm{M}=$ Male, $\mathrm{F}=$ Female, NAD = No Abnormality Detected

A few incidental pathological treatment findings unrelated to treatments (unilateral undersized and underweight testes and epididymis) were found. The summary of the histopathological changes noticed in organs of individual animals has been tabulated in Table 10.

Table 10. Summary of histopathology findings.

\begin{tabular}{|c|c|c|c|c|c|c|c|c|c|}
\hline \multirow{3}{*}{$\begin{array}{l}\text { Sex } \\
\text { Group }\end{array}$} & \multicolumn{2}{|l|}{ Male } & \multicolumn{2}{|c|}{ Female } & \multirow{3}{*}{$\begin{array}{l}\text { Sex } \\
\text { Group }\end{array}$} & \multicolumn{2}{|l|}{ Male } & \multicolumn{2}{|c|}{ Female } \\
\hline & G1 & G5 & G1 & G5 & & G1 & G5 & G1 & G5 \\
\hline & VC & IND02-100 & VC & IND02-100 & & VC & IND02-100 & VC & IND02-100 \\
\hline $\begin{array}{l}\text { Number of rats } \\
\text { Examined }\end{array}$ & 5 & 5 & 5 & 5 & $\begin{array}{l}\text { Number of rats } \\
\text { Examined }\end{array}$ & 5 & 5 & 5 & 5 \\
\hline Lungs & & & & & Prostate & & & & \\
\hline $\begin{array}{l}\text { Infiltration, lymphoid, } \\
\text { minimal }\end{array}$ & 1 & NAD & NAD & NAD & $\begin{array}{l}\text { Infiltration, lymphoid, } \\
\text { interstitial, minimal }\end{array}$ & 1 & NAD & - & - \\
\hline Heart & & & & & Epididymides & & & & \\
\hline $\begin{array}{l}\text { Infiltration, inflammatory cell, } \\
\text { myocardium, minimal }\end{array}$ & 2 & 1 & 1 & NAD & $\begin{array}{l}\text { Infiltration, lymphoid, } \\
\text { minimal }\end{array}$ & 1 & NAD & - & - \\
\hline Adrenal & & & & & Stomach & & & & \\
\hline Vacuolation, cortical, minimal & 3 & 1 & NAD & NAD & Glandular dilation & NAD & 1 & 1 & NAD \\
\hline Cyst, capsule & NAD & NAD & NAD & 1 & Cyst & NAD & NAD & 1 & NAD \\
\hline Liver & & & & & Thyroid & & & & \\
\hline Infiltration, lymphoid, minimal & 1 & 1 & 2 & 3 & Cystic glands & NAD & NAD & 1 & NAD \\
\hline Kidneys & & & & & Rectum & & & & \\
\hline $\begin{array}{l}\text { Infiltration, lymphoid, } \\
\text { interstitial, minimal }\end{array}$ & NAD & 1 & NAD & NAD & $\begin{array}{l}\text { Hyperplasia, } \\
\text { Lymphoid, mild }\end{array}$ & 1 & NAD & NAD & 1 \\
\hline Eyes & & & & & Mandibular Lymph node & & & & \\
\hline Retinal rosettes & 1 & 2 & NAD & NAD & $\begin{array}{l}\text { Hyperplasia, lymphoid, } \\
\text { follicular, mild }\end{array}$ & NAD & NAD & 1 & NAD \\
\hline Retinal folds & 1 & NAD & NAD & NAD & Plasmacytosis, mild & NAD & NAD & 1 & NAD \\
\hline Pituitary & & & & & Jejunum & & & & \\
\hline Cysts, multiple & 2 & 1 & 2 & 3 & Hyperplasia, Lymphoid, mild & NAD & NAD & NAD & 1 \\
\hline Thymus & & & & & Spleen & & & & \\
\hline Cyst & NAD & NAD & 1 & NAD & Lymphoid atrophy & NAD & 1 & NAD & NAD \\
\hline Abdominal skin & & & & & Uterus & & & & \\
\hline $\begin{array}{l}\text { Infiltration, lymphoid, intramuscular, } \\
\text { minimal }\end{array}$ & NAD & NAD & NAD & 1 & Epithelial vacuole & - & - & NAD & 1 \\
\hline Trachea & & & & & Nasal passage & & & & \\
\hline Dilation, glandular, minimal & 1 & NAD & NAD & NAD & Hyperplasia, goblet cell, minimal & 5 & 5 & 5 & 5 \\
\hline
\end{tabular}

$\mathrm{NAD}=$ No Abnormality Detected.

during the present study. All the values in both IND02-NS or VC groups during laboratory evaluations were found within the normal ranges of historical values of performing laboratory. The incidental and reversible changes were found in IND02-NS treated rats in some hematology parameters. However, the changes were reversible and not dose- or gender- or treatment-dependent. For example, mild reversible changes in prothrombin time in $100 \mu \mathrm{g} / \mathrm{rat} /$ day males were found but not in female rats were found.

Similarly, a significant increase in eosinophil count in dose level of $50 \mu \mathrm{g} / \mathrm{rat} / \mathrm{day}$ in IND02-NS treated female rats but not in male rats in any dose levels. There were a significant decrease in urea and blood urea nitrogen levels in $50 \mu \mathrm{g} / \mathrm{rat} /$ day and $100 \mu \mathrm{g} / \mathrm{rat} /$ day dose levels. However, these changes were not correlated to changes in urinalysis, gross pathology, or histopathology of kidneys.

The effects of intranasal IND02-NS administration on the histopathology of the nasal passage (nasopharyngeal tissues up to 4 levels, one level each to include nasopharyngeal duct and nasalassociated lymphoid tissue) was evaluated during the present study. The minimal level of goblet cell hyperplasia observed in the respiratory epithelium lining the nasal septum (level 1)of the nasal passage Such observations are expected as an adaptive response to intranasal exposure and not considered to be toxicologically relevant. Taken 
together, intranasal IND02-NS administration at and up to the dose of $100 \mu \mathrm{g} / \mathrm{rat} /$ day throughout 28 days did not induce any significant gross pathological or histopathological changes. Therefore, the dose level of $100 \mu \mathrm{g} / \mathrm{rat} /$ day can be considered the no-adverse-event-level (NOAEL) for intranasal IND02-NS administration.

Plant-based polyphenols, particularly proanthocyanins, have exhibited a wide range of pharmacological actions, including antioxidant, anticarcinogenic, cardioprotective, antibacterial, antiviral, and neuroprotective properties ${ }^{42}$. Safety of orally administrated polyphenols from various plant extracts has been reported in the past ${ }^{43-}$ ${ }^{45}$. The acute oral administration of polyphenol based green tea extract showed a median lethal dose $\left(\mathrm{LD}_{50}\right)$ greater than $2,170 \mathrm{mg} / \mathrm{kg}$ in mice ${ }^{43}$ with a NOAEL greater than $2,500 \mathrm{mg} / \mathrm{kg}$ in mice for 28 days with no mortality or signs of toxicity ${ }^{44}$. Past report on polyphenols-based apple extract showed no significant hematological, clinical, chemical, histopathological, or urinary effects at a $2000 \mathrm{mg} / \mathrm{kg}$ dose during an acute oral-toxicity test and 90 -day subchronic-toxicity test ${ }^{45}$. To our knowledge, the present study is the first to demonstrate the safety of polyphenols-based cinnamon bark extract on intranasal administration at the MTD of $100 \mu \mathrm{g} /$ rat (acute toxicity test) and NOAEL of $100 \mu \mathrm{g} /$ rat/day (28-day repeated dose toxicity study).

Anosmia (loss of the sense of smell, either total or partial) or hyposmia (a reduced ability to smell and to detect odors) are some of the conditions experienced by patients involving nasal infection or blockage of the nose such as allergies, nasal polyps, viral infections and head trauma ${ }^{46}$. Furthermore, irritant chemicals such as zinc may affect the olfactory nerve resulting in altered smell ${ }^{47-49}$. Therefore, the ability to maintain a sense of smell is an essential safety characteristic of nasal products. The buried food test is a reliable protocol for the sense of smell evaluations 37,50 that relies on animal's natural tendency to use olfactory cues for foraging and the ability to smell volatile odors ${ }^{37}$. The rats can discriminate between specific odors and have spatial navigation towards them ${ }^{51}$. In the present study, intranasal subacute (28-days) administration of IND02-NS (up to $100 \mu \mathrm{g} / \mathrm{rat} /$ day) did not have any effect on the sense of smell in rats during the buried food test.

\section{CONCLUSION}

The present study demonstrated the safety of intranasal acute and subacute (28-day repeated dose) administration of polyphenols based standardized cinnamon bark extract (IND02-NS) without any effect on the sense of smell in laboratory rats. The maximum tolerated dose during acute intranasal administration of IND02-NS was found to be greater than $100 \mu \mathrm{g} / \mathrm{rat}$. The no-adverse-event level of intranasal administration of IND02-NS for 28 days to rats was found to be equal to or greater than $100 \mu \mathrm{g} / \mathrm{rat} /$ day.

\section{ACKNOWLEDGEMENT}

We would like to acknowledge Intox Pvt. Ltd., Pune, Maharashtra, India, for their contract research services.

\section{CONFLICTS OF INTEREST}

None.

\section{SUPPORT}

The study is supported by Indus Biotech Private Limited, Pune, India.

\section{ABBREVIATIONS}

AR: Allergic rhinitis; AINT: Acute intranasal toxicity; IL-4: Interleukin 4, IND02: polyphenols based standardized cinnamon bark extract; MTD: the maximum tolerated dose; NOAEL: The no-observedadverse-effect-level, OECD: Organization for Economic Co-operation and Development, QoL: quality-of-life, SD: Standard Deviation; VC: Vehicle control group; VC-R: Vehicle control - Reversal group

\section{REFERENCES}

1. Chaudhry NMA, Tariq P. Anti-microbial activity of Cinnamomum cassia against diverse microbial flora with its nutritional and medicinal impacts. Pakistan Journal of Botany. 2006;38:169.

2. Gayoso C, Lima E, Oliveira $V$, et al. Sensitivity of fungi isolated from onychomycosis to Eugenia cariophyllata essential oil and eugenol. Fitoterapia. 2005;76:247-249.

3. Samarasekera R, Kalhari KS, Weerasinghe IS. Mosquitocidal activity of leaf and bark essential oils of Ceylon Cinnamomum zeylanicum. Journal of Essential Oil Research. 2005;17:301-303.

4. Anderson RA, Zhan Z, Luo R, et al. Cinnamon extract lowers glucose, insulin and cholesterol in people with elevated serum glucose. Journal of traditional and complementary medicine. 2016;6:332-336.

5. Borzoei A, Rafraf M, Niromanesh S, Farzadi L, Narimani F, Doostan $F$. Effects of cinnamon supplementation on antioxidant status and serum lipids in women with polycystic ovary syndrome. Journal of traditional and complementary medicine. 2018;8:128-133.

6. Hasanzade F, Toliat M, Emami SA, Emamimoghaadam Z. The Effect of Cinnamon on Glucose of Type II Diabetes Patients. Journal of traditional and complementary medicine. 2013;3:171-174.

7. Shen $Y$, Jia LN, Honma N, Hosono T, Ariga T, Seki T. Beneficial effects of cinnamon on the metabolic syndrome, inflammation, and pain, and mechanisms underlying these effects - a review. Journal of traditional and complementary medicine. 2012;2:27-32.

8. Kalemba D, Kunicka A. Antibacterial and antifungal properties of essential oils. Current Medicinal Chemistry. 2003;10:813-829.

9. Kurokawa M, Kumeda CA, Yamamura J-i, Kamiyama T, Shiraki K. Antipyretic activity of cinnamyl derivatives and related compounds in influenza virus-infected mice. European journal of pharmacology. 1998;348:45-51

10. Mau J-L, Chen C-P, Hsieh P-C. Antimicrobial effect of extracts from Chinese chive, cinnamon, and corni fructus. Journal of Agricultural and Food Chemistry. 2001;49:183-188

11. Mishra AK, Mishra A, Kehri H, Sharma B, Pandey AK. Inhibitory activity of Indian spice plant Cinnamomum zeylanicum extracts against Alternaria solani and Curvularia lunata, the pathogenic dematiaceous moulds. Annals of clinical microbiology and antimicrobials. 2009;8:9.

12. Newall CA, Anderson LA, Phillipson JD. Herbal medicines. A guide for health-care professionals: The pharmaceutical press; 1996.

13. Singh G, Maurya S, Delampasona M, Catalan CA. A comparison of chemical, antioxidant and antimicrobial studies of cinnamon leaf and bark volatile oils, oleoresins and their constituents. Food and chemical toxicology. 2007;45:1650-1661

14. Mancini-Filho J, Van-Koiij A, Mancini D, Cozzolino F, Torres R Antioxidant activity of cinnamon (Cinnamomum zeylanicum, Breyne) extracts. Bollettino chimico farmaceutico. 1998;137:443.

15. Warrier $P$, Nambiar V, Ramankutty C. Indian medicinal plants: a compendium of 500 species: Orient Blackswan; 1996.

16. Fine AM. Oligomeric proanthocyanidin complexes: history, structure, and phytopharmaceutical applications. Alternative medicine review: a journal of clinical therapeutic. 2000;5:144.

17. Cao H, Urban JF, Anderson RA. Cinnamon polyphenol extract affects immune responses by regulating anti-and proinflammatory and glucose transporter gene expression in mouse macrophages. The Journal of nutrition. 2008;138:833-840.

18. Cao H, Anderson RA. Cinnamon polyphenol extract regulates tristetraprolin and related gene expression in mouse adipocytes. Journal of Agricultural and Food Chemistry. 2011;59:2739-2744. 
19. Shan B, Cai Y-Z, Brooks JD, Corke H. Antibacterial properties and major bioactive components of cinnamon stick (Cinnamomum burmannii): activity against foodborne pathogenic bacteria. Journal of Agricultural and Food Chemistry. 2007;55:5484-5490

20. Beecher GR. Proanthocyanidins: Biological activities associated with human health. Pharmaceutical Biology. 2004;42:2-20.

21. Muhammad DRA, Dewettinck K. Cinnamon and its derivatives as potential ingredient in functional food-A review. International journal of food properties. 2017;20:2237-2263.

22. da Silva MLT, Bernardo MAS, Singh J, de Mesquita MF. Beneficial uses of cinnamon in health and diseases: An interdisciplinary approach. The Role of Functional Food Security in Global Health: Elsevier; 2019:565-576.

23. Balekar N, Bodhankar SL, Mohan V, Thakurdesai PA. Modulatory activity of a polyphenolic fractions of Cinnamomum zeylanicum L. bark on multiple arms of immunity in normal and immunocompromised mice. Journal of Applied Pharmaceutical Science. 2014;4:114-122.

24. Prakash E, Lambotin M, Fauvelle C, et al. Inhibition of Hepatitis C Virus infection by IND02, a natural compound derived from Cinnamon. Single Theme Conference on HCV infection and disease and recent advances in liver diseases. New Delhi, India2015.

25. Fauvelle C, Lambotin M, Heydmann L, et al. A cinnamon-derived procyanidin type A compound inhibits hepatitis $C$ virus cell entry. Hepatol. Int. 2017

26. Connell BJ, Chang S-Y, Prakash E, et al. A Cinnamon-Derived Procyanidin Compound Displays Anti-HIV-1 Activity by Blocking Heparan Sulfate- and Co-Receptor- Binding Sites on gp120 and Reverses T Cell Exhaustion via Impeding Tim-3 and PD-1 Upregulation. PLoS One. 2016;11:e0165386.

27. Biedma ME, Connell B, Schmidt S, et al. Anti-HIV and immune modulating activities of IND02. AIDS Vaccine 2012. Boston Convention Center, Boston, USA2012.

28. Lin WL, Guu SY, Tsai CC, et al. Derivation of Cinnamon Blocks Leukocyte Attachment by Interacting with Sialosides. PLoS One. 2015:10:e0130389.

29. Kandhare AD, Aswar U, Mohan V, Thakurdesai PA. Ameliorative effects of type-A procyanidine polyphenols from cinnamon bark in compound 48/80-induced mast cell degranulation. Anatomy and Cell Biology. 2017;50:275-284

30. Aswar U, Kandhare A, Mohan V, Thakurdesai PA. Anti-allergic Effect of Intranasal Administration of Type-A Procyanidine Polyphenols Based Standardized Extract of Cinnamon Bark in Ovalbumin sensitized BALB/c Mice. Phytotherapy Research. 2015;29:23-433.

31. Walanj S, Walanj, Aparna, Mohan V, Thakurdesai PA. Efficacy and safety of intranasal cinnamon bark extract in seasonal allergic rhinitis patients: A double-blind placebo-controlled pilot study. Journal of Herbal Medicine. 2014;4:37-47

32. Steels E, Steels E, Deshpande P, Thakurdesai P, Dighe S, Collet T. A randomized, double-blind placebo-controlled study of intranasal standardized cinnamon bark extract for seasonal allergic rhinitis. Complementary Therapies in Medicine. 2019;47:102198.

33. Singleton V, Rossi Jr J. Colorimetry of total phenolics with phosphomolybdic-phosphotungstic acid reagents. American journal of Enology and Viticulture. 1965;16:144.

34. Turner PV, Brabb T, Pekow C, Vasbinder MA. Administration of substances to laboratory animals: routes of administration and factors to consider. Journal of the American Association for Laboratory Animal Science : JAALAS. 2011:50:600-613.
35. Erdo F, Bors LA, Farkas D, Bajza A, Gizurarson S. Evaluation of intranasal delivery route of drug administration for brain targeting. Brain research bulletin. 2018;143:155-170

36. Organisation for Economic Co-operation and Development. Test No. 407: Repeated Dose 28-day Oral Toxicity Study in Rodents. OECD Guidelines for the Testing of Chemicals, Section 4: Health Effects. Paris: OECD Publishing; 1998:1.

37. Yang M, Crawley JN. Simple behavioral assessment of mouse olfaction. Current protocols in neuroscience. 2009;Chapter 8:Unit 8 24.

38. Harkema JR, Carey SA, Wagner JG. The nose revisited: a brief review of the comparative structure, function, and toxicologic pathology of the nasal epithelium. Toxicol Pathol. 2006;34:252-269.

39. Pawankar R, Canonica G, Holgate S, Lockey R. Introduction and Executive Summary In: Pawankar R, Canonica G, Holgate S, Lockey $\mathrm{R}$, eds. WAO white book on allergy. Milwaukee, Wisconsin, USA World Allergy Organisation; 2011:12.

40. Stuck BA, Czajkowski J, Hagner A-E, et al. Changes in daytime sleepiness, quality of life, and objective sleep patterns in seasonal allergic rhinitis: a controlled clinical trial. Journal of allergy and clinical immunology. 2004;113:663-668.

41. Wu EL, Harris WC, Babcock CM, Alexander BH, Riley CA, McCou ED. Epistaxis Risk Associated with Intranasal Corticosteroid Sprays: A Systematic Review and Meta-analysis. Otolaryngology--head and neck surgery : official journal of American Academy of OtolaryngologyHead and Neck Surgery. 2019;161:18-27.

42. Aron PM, Kennedy JA. Flavan-3-ols: Nature, occurrence and biological activity. Molecular nutrition \& food research. 2008;52:79-104.

43. Sarker SA, Sultana S, Pietroni M, Dover A. Safety of a bioactive polyphenol dietary supplement in pediatric subjects with acute diarrhoea. International journal of pediatrics. 2015;2015.

44. Hsu Y-W, Tsai C-F, Chen W-K, Huang C-F, Yen C-C. A subacute toxicity evaluation of green tea (Camellia sinensis) extract in mice. Food and Chemical Toxicology. 2011;49:2624-2630

45. Shoji T, Akazome $Y$, Kanda T, Ikeda M. The toxicology and safety of apple polyphenol extract. Food and chemical toxicology. 2004;42:959967.

46. Simmen D, Briner HR. Olfaction in rhinology--methods of assessing the sense of smell. Rhinology. 2006;44:98-101.

47. Rea P. Chapter 1 - Introduction to the Nervous System. Essentia Clinical Anatomy of the Nervous System. San Diego: Academic Press; 2015:1-50.

48. Blakemore LJ, Trombley PQ. Zinc as a Neuromodulator in the Centra Nervous System with a Focus on the Olfactory Bulb. Frontiers in cellular neuroscience. 2017;11:297.

49. Hamidovic A. Position on zinc delivery to olfactory nerves in intranasal insulin phase I-III clinical trials. Contemporary clinical trials. 2015;45:277-280.

50. Rattazzi L, Cariboni A, Poojara R, Shoenfeld $Y$, D'Acquisto F. Impaired sense of smell and altered olfactory system in RAG-1(-/-) immunodeficient mice. Frontiers in Neuroscience. 2015;9:318.

51. Wallace DG, Gorny B, Whishaw IQ. Rats can track odors, other rats, and themselves: implications for the study of spatial behavior. Behavioural brain research. 2002:131:185-192. 


\section{GRAPHICAL ABSTRACT}

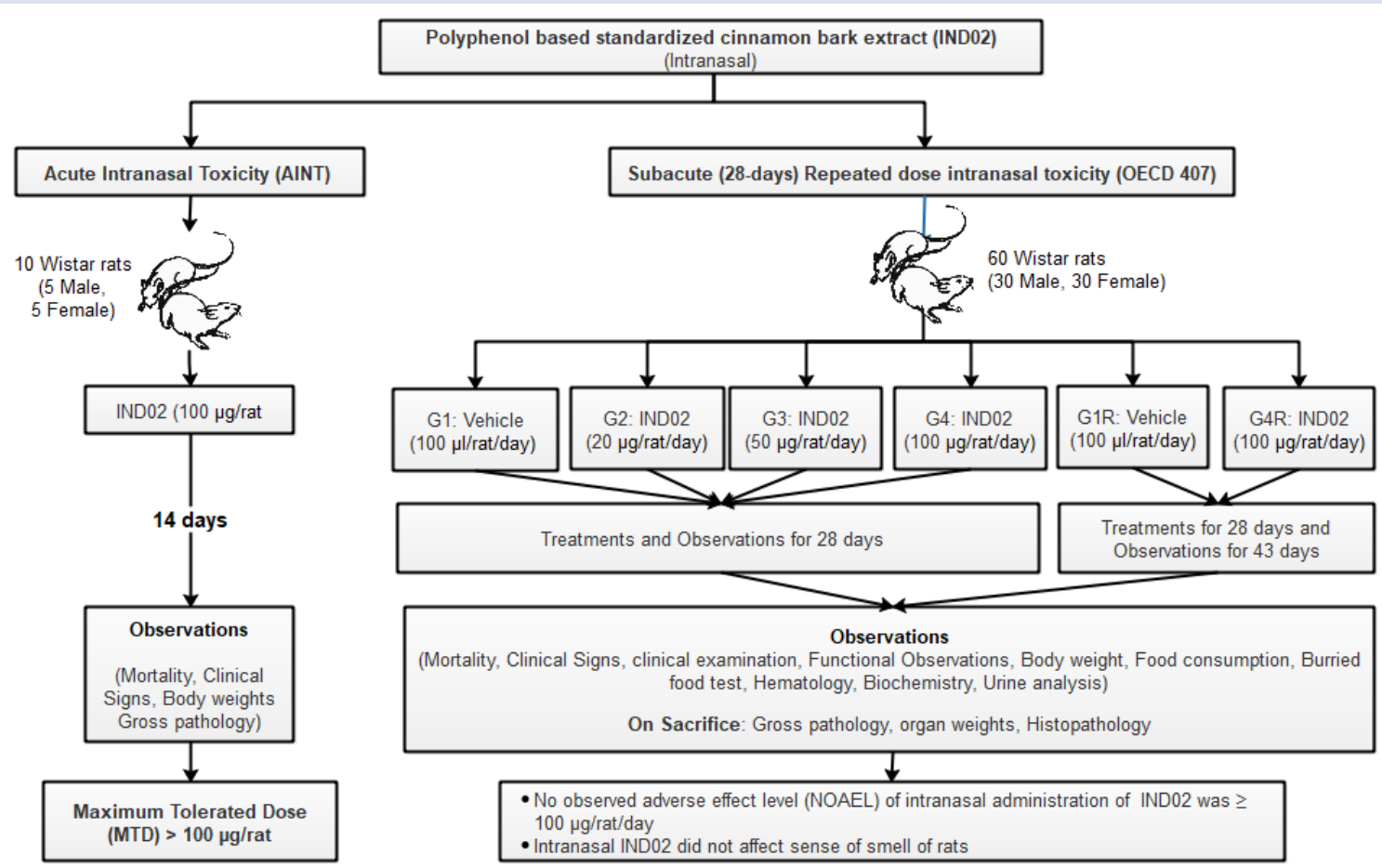

\section{SUMMARY}

- Acute and subacute (28-days) intranasal toxicity of standardized cinnamon bark extract (IND02-NS) in rats were evaluated

- The acute maximum tolerated dose (MTD) of intranasal IND02-NS was greater than $100 \mu \mathrm{g} / \mathrm{rat} /$ day.

- No observed adverse effect level (NOAEL) of subacute intranasal IND02-NS was greater than $100 \mu \mathrm{g} / \mathrm{rat} / \mathrm{day}$.

- IND02-NS was found safe at a dose of $100 \mu \mathrm{g} / \mathrm{rat} /$ day during acute and subacute (28 days repeated dose) intranasal administration in rats.

\section{ABOUT AUTHORS}

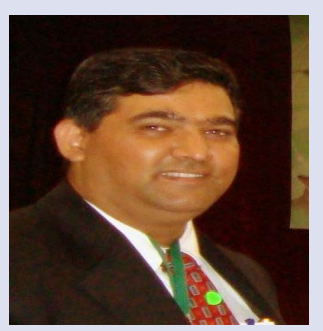

Dr. Prasad Thakurdesai, Chief Scientific Officer, Indus Biotech Private Limited, Pune, India, acquired the B. Pharm, M. Pharm. and PhD in Pharmaceutical Sciences from Nagpur University, Nagpur, India. He has 17 years of academic and 13 years of Industrial experience. He has more than 100 journal publications, 59 conference presentations, 8 awards, one book, 2 book chapters, 11 popular science magazine articles, and more than 30 invited lectures at conferences, workshops or exhibitions to his credit. He has guided $4 \mathrm{PhD}$ and more than $32 \mathrm{M}$. Pharm students for their dissertations. He is a member of many professional organizations of pharmaceutical sciences, Quality of Life, Toxicology and Community Pharmacy.

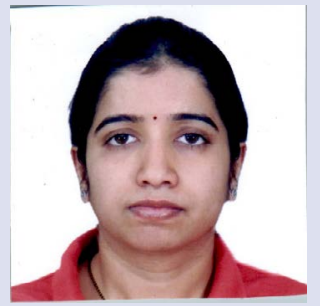

I am Pallavi Deshpande and have done my graduation and post-graduation in Pharmacy at SNDT University, Mumbai. I am currently working with Indus Biotech Private Limited, Pune in Scientific Affairs department. Our company deals with research on compounds derived from food chain raw materials with in-depth research including invitro studies, preclinical efficacy \& safety studies, and clinical studies and publishing them in PubMed abstracted journals. I had earlier experience in coordinating clinical studies with Cipla, Mumbai. Currently, I have 12 journal publications with 7 conference publications. 